\title{
SEXUALIDADE E ETARISMO: \\ análise do discurso em uma lista de debates na Internet
}

\author{
Anna Cruz de Araújo Pereira da Silva ${ }^{1}$ \\ Aline da Silva Pedrosa ${ }^{2}$
}

\section{Resumo}

Neste artigo analisam-se os discursos sobre sexualidade e velhice em um foro de debates na Internet, um espaço em que a ausência de controles à fala permite revelar preconceitos e reforçar mitos e estereótipos. Para tanto, 11 excertos (três perguntas e oito respostas) foram coletados em novembro de 2007 no foro Yahoo-Respostas a partir da busca combinada das palavras "idoso + sexo", "idosa + sexo", "velho + sexo", "velha + sexo", confrontandose estes trechos a outros textos e bibliografias. Verificou-se que, apesar do discurso predominante etarista, de negação e exclusão do indivíduo idoso, começam a surgir falas dissonantes, arrimadas em uma nova perspectiva, de afirmação e inclusão, decorrente das contribuições da Gerontologia e dos Direitos Humanos, que se firmam não apenas como campos do conhecimento, mas ainda como ideários em defesa da diversidade.

Palavras-chave: Envelhecimento. Sexo. Preconceito. Gerontologia. Direitos humanos.

\section{Introdução}

Neste artigo analisam-se as representações do exercício da sexualidade na velhice através dos discursos de usuários da Internet, a rede mundial de computadores. Sexualidade e velhice são ainda temas interditos, sobre os quais não se pode dizer tudo, nem em todo lugar, nem tampouco a qualquer um (FOUCAULT, 1996); no entanto, nos foros de debates virtuais, onde os falantes trocam suas identidades reais por nicknames, censura, pressões ou controles morais, éticos, legais e mesmo gramaticais desvanecem-se: a palavra está franqueada e, a despeito da impossibilidade de instrumentá-la com gestual ou sonoridade, sua performance é liberada à plenitude, com uso de expedientes como escrita em letras capitais para ênfase, gargalhadas onomatopéicas, etc.

\footnotetext{
1 Advogada, especialista em Geriatria e Gerontologia (UERj), mestranda do Programa de Pós Graduação em Direito da Universidade Federal do Pará (UFPa). E-mail: hilton.anna@gmail.com

2 Psicóloga, mestre em Gerontologia Social (PUC-SP). E-mail: alineadv@hotmail.com
} 
Os fóruns de discussão são muito procurados pelas pessoas que navegam na web. Um fórum é um espaço virtual dentro de um site, no qual pode-se postar uma mensagem sobre determinado tema. Muitas dessas pessoas acompanham de perto essas discussões, voltando várias vezes ao site, postando suas mensagens, que podem ter freqüência diária. (CAMPOS, 2004a, p. 143).

No foro de debates escolhido para a presente análise, em particular, não se dispõe de mais detalhadas informações sobre o participante: não há dados sobre idade, sexo, nível sócio-econômico ou lugar, havendo apenas um nickname - e "[ . . ] é o nick que vai expressar quem é essa pessoa, uma vez que não temos outra forma de conhecê-la." (CAMPOS, 2004b, p. 118). Nesta modalidade, a interação entre os usuários é sincrônica ou assincrônica e permitem-se réplicas, tréplicas e dinamismo interagente (ao contrário, por exemplo, do que em geral ocorre em blogs ou sites de busca de parceiros afetivos).

Na Internet, a "polícia discursiva" (FOUCAULT, 1996) é mais branda, o que enseja maior abertura às regiões do discurso. É assim que os sujeitos sentem-se à vontade para penetrar em sendas que, noutros contextos, exigiriam qualificação prévia para que fosse garantida validade ao pronunciado (p. ex.: elencar remédios que servem a uma ou outra finalidade, diagnosticar possíveis doenças, etc.). A acessibilidade ilimitada garante espaço profícuo para o desenvolvimento de formas de comunicação, mas é de notar que na internet reproduzem-se a hegemonia da voz dominante, a prevalência do discurso em voga, a vinculação a interesses majoritários (MELO, 2004).

Deste modo, o discurso espontâneo sobre sexualidade na velhice revela indiscretos preconceitos e a repetição de mitos populares acerca de idosos assexuados, idosos sem vivência amorosa, abnegação sexual em favorecimento de uma experiência religiosa, ou, por outro lado, idosos pervertidos, idosos para quem o sexo só existe em caráter negocial, etc.

Entretanto, principia a se constituir, em ruptura, um novo relato sobre sexualidade na velhice, apoiado pelo ideal de Direitos Humanos e pelo conhecimento gerontológico, relativizando padrões e propondo novos estilos de vida. Esta nova voz começa a ganhar reverberação nos debates virtuais, o que provoca contraponto e dissonância na monofonia (MELO, 2004). 


\section{Os Fios de Preconceito da Rede}

Para análise de discurso, recolhemos, em novembro de 2007, onze excertos, sendo três perguntas e oito respostas, de usuários do foro YahooRespostas, confrontando a eles outros textos e bibliografias. Este foro foi o escolhido por ser o único conhecido em português a permitir que membros cadastrados façam perguntas acerca de 26 categorias temáticas (viagem, governo e política, família e relacionamento, etc.) às quais respostas elaboradas por outros membros cadastrados são sugeridas, sendo ambas, perguntas e respostas, de acesso público - de leitura aberta a usuários e não-usuários, portanto. Assim, ao se proporem questões e ao se ofertarem esclarecimentos, tem-se, a princípio, o espaço adequado de polemização e desconstrução de certezas cristalizadas.

O Yahoo-Respostas define-se como "[ . . . ] uma comunidade online na qual os participantes podem fazer perguntas para obter respostas sobre uma grande variedade de temas" cujo objetivo "[ . . . e é ser uma base de dados de conhecimento gerado pelos usuários [ . . . ]", vedando expressamente "[ ... ] qualquer tipo de conteúdo que infrinja os direitos de crianças e adolescentes" (não há menção aos direitos dos idosos), "[ . . . ] qualquer tipo de conteúdo vulgar, obsceno, sexualmente explícito, com palavrões ou linguagem de baixo-calão [ . . . ] qualquer tipo de conteúdo preconceituoso, racista ou discriminatório contra qualquer pessoa ou grupo de pessoas" e ainda "[ ... ] qualquer tipo de conteúdo que infrinja qualquer lei brasileira", reservando-se o direito, em caso de violação destas regras, de remover o conteúdo infringente e, " [ . . . ] em caso de reincidência, independente do nível em que se encontra, independente de aviso, a conta do usuário também será suspensa do Yahoo! Respostas", podendo ainda haver, a depender da gravidade da violação, desativação da conta do usuário no Yahoo!, o que acarretará conseqüente perda de todo o conteúdo associado, incluindo " [...] E-mails, Perfis, Álbuns de Fotos, Grupos e sites do Geocities." (YAHOO! RESPOSTAS, c2008).

Os trechos foram eleitos a partir dos resultados de busca empreendida no conteúdo do site através da combinação de palavras "idoso + sexo", "idosa + sexo", "velho + sexo", "velha + sexo". A transcrição preserva a íntegra das escritas originais e os nicknames também são mantidos, sem que isto importe violação à intimidade dos usuários, já que as manifestações são públicas e as identidades reais permanecem resguardadas sob os nomes de fantasias. A seguir, o primeiro grupo de perguntas e respostas sobre a temática selecionada, "sexualidade e velhice". 
Pergunta A: "Numa sociedade igualitária e sexualmente liberada, quem traça as idosas? (ElvisPelvis39)".

Respostas: 1. "sem essa cara, se a idosa tiver estabilidade (dindin), vai achar um belo rapaz e termina tudo e as que nada tem, se conforma em rezar, ir a igreja com mais frequência e nem pensa no sexo, diz que o cachimbo apagou. e quando a coisa aperta, se toca na hora do banho etc... (Lucas)";

2. “Os vovófilos. $k k k k k k k k k k k k k k k k k k k$... tá procupado com a velhice, hein???!!! kkkkkkkkkkk....se vc morrer novo, não vai passar por essa preocupação. kkkkkkkkkkkk (Perfumista)" (YAHOO! RESPOSTAS, 2007b, nosso grifo).

A pergunta A, enquadrada na categoria "Família e Relacionamentos", apresenta um tom faceto, pois se inicia com preliminar séria, aparentemente cuidadosa com a escolha de palavras, mas logo dá um giro e surpreende com a indagação "quem traça as idosas?", na qual a palavra "traça" transmite sentido obsceno, aviltante. A tal pergunta, contudo, são oferecidas respostas, o que demonstra que ela é acolhida, considerada válida.

$\mathrm{Na}$ elaboração da pergunta $\mathrm{A}$, o usuário anônimo supostamente admite viver em sociedade igualitária e sexualmente liberada. No entanto, vale examinar a pergunta: se a sociedade é de fato igualitária, o que faz esta pessoa assumir como diferenciada a sexualidade das mulheres idosas? Vale observar que o usuário refere-se especificamente às mulheres e não aos homens; o homem idoso não é fator de preocupação neste caso, mas a mulher idosa. Há um fio de preconceito sexista disfarçado?

A resposta 1, em sua primeira parte, não apenas assume que o sexo só é possível mediante pagamento, como reforça a concepção de que idosos desejam relacionar-se com pessoas mais jovens, embora não sejam atraentes a elas. Àquelas senhoras que não têm possibilidade de pagar por sexo restaria o desvio do impulso sexual para a conformação religiosa ou a excitação solitária - a velhice seria, assim, o tempo do alheamento.

A estabilidade financeira aparece, então, como garantia de satisfação, bem como reforça a concepção imposta pelo capitalismo de que não apenas os idosos, mas as pessoas em geral obtêm realização a partir do poder financeiro.

A resposta 2 é pontuada por demoradas gargalhadas virtuais, indicando que a sexualidade na velhice é anedótica. Marca-se também pelo neologismo "vovófilos", os que têm amor ou desejo sexual por "vovós". 
O usuário da resposta 2 expõe pejorativamente o processo de negação da sexualidade para os idosos, referindo nas entrelinhas que, se há forma de satisfação sexual, esta se dá através do desejo do outro, ou seja, pela "vovofilia" do outro. Assume ainda que a morte é solução para não sofrer esse tipo de preocupação, em um raciocínio de extrema exclusão do idoso (espécie de "gerontocídio" a que Brodgen [2001] faz menção).

A questão vernacular sobre qual o termo correto para designar "idoso" (e já aqui não se evita a escolha por um deles) está ainda em aberto: vovô, velho, idoso, adulto maior, inativo, aposentado, terceira idade, melhor idade, ancião, senil, etc. não são, no entanto, palavras justamente intercambiáveis.

Peixoto (2007) afirma que as locuções diferenciadas importam sentidos distintos: na França, vieux (velho) era mais comumente usado para aquele que não tinha status social, enquanto personne agée (idoso) era usado para aquele que o tinha; no Brasil, a substituição de "velho" por "idoso" também é tributária de um movimento por mais respeito e valorização.

É importante considerar que o termo "velho" remete-nos a significados subjetivos e variados, ora referindo a valor, ora a identidade, o que gera receio em usar a palavra devido à conotação em geral negativa atribuída pela sociedade. Por outro lado, Peixoto registra que certos analistas crêem que o termo "idoso" é o ambíguo, por caracterizar "[ . . . ] tanto a população envelhecida em geral, quanto os indivíduos das camadas mais favorecidas." (PEIXOTO, 2007, p. 73).

Costa (1998) cita como palavras relacionadas: velho, velhice, velhote, senil, senilidade, idoso, geronto, ancião, anciania, decrépito, senescente; considera "senescência" a velhice normal e "senilidade" a patológica, não distingue entre "idoso", "velho" ou "geronto", mas toma "ancião" por alguém muito idoso.

Em adição, levantando definições dicionarizadas da palavra "idoso", temos: que tem bastante idade, velho; e acerca da palavra "velho": muito idoso; antigo; que tem muito tempo de existência; gasto pelo uso; experimentado, veterano; que há muito exerce uma profissão ou tem certa qualidade; desusado, obsoleto; homem idoso; pai (FERREIRA, 2000).

Sustentamos que "velho" é adjetivo cujo uso serve a uma diversidade de objetos, qualificando tudo aquilo que não é "novo" ou que está gasto ("carro velho", "sapato velho"), enquanto que "idoso" é adjetivo próprio para seres animados, sobretudo humanos, que não sejam mais "jovens" ("homem idoso", "mulher idosa", "cão idoso"). Ademais, "idoso" é a palavra em uso corrente na legislação brasileira e nas associações de categoria (Estatuto do 
Idoso, Política Nacional do Idoso, Associação de Idosos, Conselho Municipal de Idosos, etc.), enquanto que "velho" torna-se menos freqüente em textos oficiais e no discurso identitário.

No foro de debates, o gracejo de perguntas e respostas parece enquadrar-se no discurso lúdico da tipologia de Orlandi (1996), havendo total disponibilidade sobre o que se pergunta e o que se responde, multiplicidade de sentidos e nenhum balizamento para os interlocutores. Este discurso, no entanto, é também autoritário (ORLANDI, 1996), pois enuncia estados dados, a verdade não está sendo disputada pelos interlocutores (como seria o caso do discurso polêmico): todos já sabem a resposta (velhice solitária, velhice sem sexo, velhice pervertida), até mesmo aquele que pergunta:

Pergunta B: "Será que velho faz SEXO? Por ex: Uma velha de 80 anos faria sexo? (Bom Partido)".

Respostas: 1. "É raro mas fazem, conheço dois casos, um na família e um na minha cidade que a velhinha pagou um pescador pra transar com ela (ela tinha acho que uns 80 , bem rica) e ela morreu durante a transa... (90\% angel)";

2. "Uma velha? Bem, pode até fazer, mas eu acho que dificilmente um homem quer comer uma velha de 80 anos, nem se ela pagar um prostituto! (HX)";

3. "acho que não pois já não tem tanta vontade assim pois ja esta uma pessoa cansada... (gata)";

4. "as velhas acho que naum, mas $\mathrm{p} /$ os velhos existem o viagra, levitra, etc. (luciana)" (YAHOO! RESPOSTAS, 2006, nosso grifo).

A pergunta B, inserida na categoria "Saúde Feminina", ao usar letras maiúsculas na palavra "sexo" parece demonstrar espanto, correspondendo à “será que velho seria capaz/teria coragem de fazer sexo?". Iacub (2007, p. 118) registra a permanência da " [ . . . ] impressão geral de rejeição ao erotismo na velhice $[\ldots]$ no discurso habitual, surge a referência [ainda que elíptica, como é o caso da pergunta B] à incapacidade fática para o sexual."

No mais, não é claro o que "sexo" significa para o usuário, pois a idéia de sexo para uma pessoa de 20 anos é diferenciada em relação a uma pessoa de 80 anos, bem como a de qualidade do sexo. Assim, é importante situar-se na amplidão da sexualidade humana para não incorrer no preconceito etário. 
A resposta 1 admite existir, mas ser raro, o sexo para o velho. Enumera apenas dois casos de seu conhecimento (no vasto universo de idosos no Brasil e no mundo), o que provaria quão extraordinário é o evento "fazer sexo". Novamente, no segundo exemplo, a "velhinha", "bem rica", teria pago a um pescador pela relação sexual.

Por que mencionar que o parceiro era um "pescador"? Por ser ele de status social inferior ao da idosa "bem rica"? Um idoso só pode relacionarse em assimetria, estando consigo a "vantagem" (com alguém mais jovem, alguém mais pobre, alguém doente)?

Ademais, por que é freqüente o uso de diminutivos (a "velhinha") com idosos, da mesma maneira que com crianças? É este um recurso de equiparação, como se assim eles se infantilizassem, merecessem complacência, tivessem seu discernimento prejudicado? Gusmão (2003, p. 16) afirma que: "O velho e a criança são percebidos, então, como 'seres entre duas águas marginais', entre um passado e um futuro que fazem de seu presente um enigma.”. Assim, registra Gusmão (2003), velhice e infância são condições transitivas, acessórias, e não o tempo principal - a criança ainda não é, o velho não é mais; a ambos confere-se o mesmo tratamento, o que, para Iacub (2007, p. 118), resulta em uma outra "desqualificação" através da "[ . . . ] representação terna, infantilizada e, portanto, sem sensualidade do ancião.”.

O desfecho da história de " $90 \%$ angel” (resposta 1) é trágico, como sói ser aos "marginais". O castigo final: a idosa morre durante o sexo, o que ratifica ser inadequada a relação sexual para idosos. Iacub (2007, p. 118) identifica este tipo de discurso "[ . . . ] dentro de uma lógica que pensa no velho em associação à doença e cuja sexualidade pode ser responsável por algum dano físico.". Trata-se da fase de "sanção" da narrativa que, sendo conservadora, há de punir o "mal" e os ditames "contrários à moral cristã" (FIORIN, 1990).

A resposta 2 principia com uma outra pergunta, como se quisesse certificação de que, de fato, havia compreendido bem o questionamento: "uma velha? [você tem certeza do que está perguntando?]" - e então a pausa para reflexão ("bem”), de modo a construir um raciocínio sobre tão bizarra pergunta. "HX" considera ser difícil a possibilidade de sexo para uma idosa, descartando inclusive a "solução" supostamente mais comum ("nem se ela pagar um prostituto"). É de notar ainda a constância da relação de "competência" para a "performance" (FIORIN, 1990), isto é, o poder (dinheiro) exigido para a ação (sexo). 
Assim, mesmo que exista o desejo da mulher idosa e que ela esteja apta para realizar uma relação sexual, não haveria desejo do outro por ela. Mais uma vez a sexualidade fica limitada apenas às mulheres mais jovens e surge o discurso baseado em estereótipos como "sexo não é para velhos" ou, neste caso, "para velhas".

A resposta 3 concebe a velhice como "tempo do cansaço", isento de desejo. Vale lembrar a frase "está velho e cansado", muito usada pra designar quando a pessoa, não necessariamente idosa ("parece que é velho"), não tem motivações para determinada ação. Desta maneira, é de notar que a velhice supostamente diminui a "humanidade" do indivíduo: ele se torna ou um "celenterado assexuado" ("não tem tanta vontade") ou um "ente divino", avesso ao mundano ("se conforma em rezar, ir à igreja com mais freqüência e nem pensa no sexo", resposta 1 à Pergunta A).

A resposta 4 revela, além do etarismo, o sexismo: "velhas" não fazem sexo, "velhos", sim. Reproduzem-se, de modo velado, preconceitos e papéis sociais esperados da vida inteira: em questões sexuais, aos homens tudo, às mulheres, nada. "Luciana" (interessante observar que o discurso de que as "velhas" não fazem sexo é produzido por um "nickname feminino") cita medicamentos que permitem ao "velho" manter-se ativo, reportando-se, então, a provas científicas, médicas, o que garante autoridade ao argumento.

\footnotetext{
Pergunta C: "Idoso que namora menina nova ta procurando sarna pra se coçar? (Giramundo)".

Resposta: 1. "Vc eh idoso e tah namorando uma menina nova e tah com mdo da sarna??? Huhauahsuahsushuhas. foi mal, mas me deu vontade. Tah sim, pq idoso eh com idosa! ou no asilo se for gaga... Pega mal né? Um homem q tem idade pra ser vo da mina! (WinxGirl)" (YAHOO! RESPOSTAS, 2007a, nosso grifo).
}

A pergunta $\mathrm{C}$, da categoria temática "Pesquisas e Opiniões", repete a idéia de que idosos têm "fetiches" por pessoas mais jovens, embora confirme, em consonância com a resposta 1 , ser imprópria a relação amorosa intergeracional ("pega mal").

Ao mudar o olhar agora para o homem idoso, percebemos que não aparecem tantas diferenças nas representações sobre sua vida afetiva: da mesma forma que o sexo seria "arriscado" para idosas, sobretudo em uma relação com homens mais jovens, também para os idosos namorar mulheres mais novas seria sinônimo de problemas. 
Parece que WinxGirl (resposta 1) desafia Giramundo (pergunta C), considerando ser ele um idoso a falar de suas próprias angústias, e também delimita os arranjos e trânsitos concedidos a idosos: "idoso eh com idosa! ou no asilo se for gaga"; considera, portanto, que apenas o relacionamento entre idosos é aceitável e que se o idoso encontra-se em estado debilitado, nomeado pejorativamente de "gagá", terá de ir para o asilo - outra vez mais, um raciocínio de exclusão e negação.

Todos estes fragmentos de falas constituem, unidos, um discurso preconceituoso revelador de uma formação ideológica etarista. Palmore (2004, p. 2) define etarismo ("ageism", "idadismo", "velhismo") como "[ . . . ] o último dos preconceitos, a derradeira discriminação, a mais cruel rejeição." (tradução nossa), sendo o preconceito contra pessoas idosas não só pelos mais jovens, como pelos próprios idosos, manifestando-se em " [ . . . ] uma série de estereótipos que ajudavam a sustentar a sinonímia entre velhice e cansaço, falta de interesse sexual, lentidão intelectual e falta de capacidade para aprender, improdutividade e mal-humor [sic].” (IACUB, 2007, p. 118).

É importante ressaltar que o desejo faz parte da vida do ser humano desde a primeira infância até a morte. É pelo desejo que a pessoa se faz sujeito e abandona a condição de objeto; ou seja: chega o momento em que a pessoa faz suas próprias escolhas, que antes eram orientadas pelo desejo dos pais.

Assim, deve-se levar em consideração que esse aspecto que confirma a criança enquanto ser humano, protagonista, ressoará na vida adulta e na velhice. $\mathrm{O}$ envelhecimento não é um fenômeno simplesmente biológico ou médico; o idoso é um "ser total", com valores culturais, memórias, escolhas afetivas, amorosas.

\section{Um Novo Discurso Gerontológico}

Iacub (2007) admite a criação de um novo discurso estimulador da sexualidade nos adultos mais velhos. Esse novo discurso transfere "impossibilidade", "violência", "inadequação" do interior do organismo do idoso, como inerentes a ele, para a sociedade (IACUB, 2007): os entraves não estão no indivíduo, mas sim no exterior - como a máxima que ganhou os ambientes midiáticos, "velho é o seu preconceito".

Contribuem para esta ruptura tanto o novo olhar que a Gerontologia propõe lançar sobre o envelhecimento (científico, crítico, informado) quanto a perspectiva dos Direitos Humanos (de tolerância, respeito à diversidade 
e defesa da dignidade humana), implicando mudanças em pensamento e atitudes relacionados à velhice e ao envelhecer.

A gerontologia aborda a sexualidade a partir de um discurso moderno e científico, que se defronta com outro qualificado como mítico, moralista ou puritano, e trata de apresentar a sexualidade e o envelhecimento como termos que não se excluem mutuamente. (IACUB, 2007, p. 153).

Registra Ferrari (1999, p. 199) que: “O termo 'Gerontologia' foi introduzido por Élice Metchnikoff em 1903 e significa o estudo científico do envelhecimento. O radical 'geron' significa 'homem velho', enquanto 'logo' significa 'o estudo de'." Entretanto, sendo demasiado amplo o "estudo do envelhecimento humano", a Gerontologia influencia e comunica-se com outras tantas áreas como Direito, Psicologia, Serviço Social, Educação, etc., revelando variadas interfaces interdisciplinares que a fortalecem na atuação dos interesses dos idosos, embora de certo modo "nublem" a configuração de seu campo científico próprio.

Cockerham (1997) afirma que, com o envelhecimento populacional e o crescente número de idosos ativos, bem-educados e saudáveis, haverá mudanças sobre as expectativas sociais relativas a eles e a superação de imagens negativas da velhice como um tempo infeliz, doente e solitário. Lopes define "idoso ativo" como:

Tanto aquele engajado numa atividade remunerada como o que faz parte de um grupo de teatro amador, cuida de netos, programa atividades de lazer, tem atividades esportistas, etc. Enfim, uma atividade que faça sentido para ele e de relevância social. (1998, p. 71, nosso grifo).

Palmore (2004) acredita que o interesse crescente por assuntos relacionados à velhice aumentaria também o conhecimento sobre os processos de envelhecimento, reduzindo estereótipos e preconceitos contra idosos.

Se esta tendência se sustentar, os debates na rede trilham, ainda que de modo manquejante, os primeiros passos para a compreensão e inclusão do outro, representando a curiosidade ingênua que precede o entendimento. De fato, algumas vozes dissonantes surgem mesmo naquele espaço: 
Resposta 5 à pergunta B: "Depois de ver tantas respostas bobas a esta pergunta aproveito pra esclarecer todos que a sexualidade na chamada $3^{\circ}$ idade faz igualmente parte da vida dos idosos como dos mais jovens. No entanto, é preciso ter em conta que um organismo envelhecido não tem a pujança física dum jovem, mas tem a suficiente para dar prazer a este grupo etário. Lembrem-se; o Charlot foi pai aos 80. Como se diz em Portugal-Homem velho e mulher nova dá filho até à cova. (Costa)" (YAHOO! RESPOSTAS, 2006, nosso grifo).

Destaca-se a proposta, na resposta 5, de esclarecer aos demais debatedores, reconhecendo o esforço da Gerontologia e dos Direitos Humanos na defesa de que, independentemente da idade ("faz igualmente parte da vida"), as pessoas têm necessidades - e direitos delas decorrentes - amorosas e sexuais.

Direitos sexuais " [ . . . ] são direitos humanos universais baseados na liberdade inerente, dignidade e igualdade para todos os seres humanos. Saúde sexual é um direito fundamental, então saúde sexual deve ser um direito humano básico.” (WORLD ASSOCIATION. .., 1999). As mudanças fisiológicas e as experiências vividas por cada um, no entanto, fazem com que a sexualidade não se exerça da mesma forma nem comparando jovens e idosos nem tampouco comparando os próprios jovens entre si ou idosos entre si.

Assim, pode-se afirmar que a sexualidade é subjetiva, ainda que haja uma tendência a "padrões" de comportamentos de acordo com certas exigências da sociedade. $\mathrm{O}$ direito à igualdade refere-se, portanto, a ser considerado com igual dignidade apesar da diferença e não à imposição arbitrária de "modelos", sejam eles sexuais, raciais, religiosos.

Sexualidade remete-se não apenas ao ato sexual, mas a um universo ligado aos relacionamentos interpessoais de cada ser existente, como desejos, sentimentos, tabus, valores, experiências. É importante considerar a cultura e a sociedade em que nos encontramos e à qual pertencemos para entender a diversidade de manifestações da mesma. Desta forma, no novo discurso de possibilidades afetivas ao idoso, amplia-se o repertório do que se entende por "sexualidade", enfatizando também aspectos não genitais de expressão sexual como dançar, assistir a um filme romântico, receber carinho, cuidar de si e do outro.

Neste contexto, a resposta 5 admite modificações e peculiaridades advindas do envelhecimento ("não tem a pujança física de um jovem”) a 
refletir na atividade sexual, mas não exclui a sexualidade e a capacidade de realizar o ato sexual - reconhece inclusive a capacidade de procriar, no caso masculino. A este respeito, deve-se lembrar que, pelas características fisiológicas da mulher, como a de não poder ter filhos após o período da menopausa, a tendência ao preconceito contra ela se sobressai.

\section{Conclusão/ Considerações}

Ao lado de um discurso corroborativo de estereótipos de uma velhice cansada, assexuada, pouco atraente, surge na rede mundial de computadores um novo tipo de relato que se coaduna com o ideário gerontológico (ARAÚJO, 2005) que vem sendo tecido, inclusive normativamente, a partir de empreendimentos internacionais (no âmbito da ONU, Convenções em Viena e Madri para elaboração de Planos de Ação para o Envelhecimento, além de Assembléia Geral para fixação dos princípios das Nações Unidas para o idoso, quais sejam: dignidade, auto-realização, assistência, participação e independência) e nacionais (Política Nacional do Idoso, Estatuto do Idoso, etc.).

A categoria semântica fundamental baseada na oposição velhice vs. sexualidade começa a revelar-se, afinal, como uma diferença falaciosa. Para Fiorin, “[ . . . ] são contrários apenas os termos que estão em relação de pressuposição recíproca." (1990, p. 19), como, por exemplo, parcialidade vs. totalidade, vida vs. morte; o contrário de velhice não é sexualidade, cometendo-se, assim, uma "violência semântica" ao confrontá-los como tais.

Vale pensar ainda em outro tipo de oposição freqüente: velhice vs. saúde. O processo de envelhecimento não é a mesma coisa que o processo de adoecimento: a doença acomete qualquer pessoa em qualquer faixa etária e não é uma característica de idosos - daí que, por exemplo, enfermidades que prejudiquem a prática do sexo (estritamente) ou o exercício da sexualidade (amplamente) não devam, necessariamente, ser associadas ao envelhecimento.

Conexões de idéias ao envelhecimento são, aliás, ainda confusas, equívocas e prenhes em mitos:

O termo envelhecimento remete a duas noções antitéticas. [ . . . ] Essas noções antônomas contidas no termo envelhecimento são, de um lado, as que evocam a idéia de desgaste, de enfraquecimento, de diminuição e de outra parte as que evocam a bonificação, (de que por exemplo, 
o vinho se beneficia), a maturação, o acréscimo. (MESSY, 1999, p. 17).

O Estatuto do Idoso (BRASIL, 2003) em seu art. 105, estabelece como crime " $[$. . . ] exibir ou veicular, por qualquer meio de comunicação, informações ou imagens depreciativas ou injuriosas à pessoa do idoso.", sendo a pena detenção de um a três anos e multa. Embora várias das falas dos debatedores enquadrem-se na disposição da lei, a punição por crimes ocorridos na Internet ainda é dificultada, sobretudo, pelo anonimato do infrator e pela precariedade da fiscalização.

As próprias penalidades previstas pelo foro em comento para os usuários que divulguem conteúdos incompatíveis com suas regras de vedação à discriminação e ao preconceito não foram aplicadas e, ademais, são todas elas virtuais, a mais grave implicando apenas a perda da conta do usuário.

A criação de bases legais contra o etarismo é, de todo modo, um marco oficial importante:

No caso do segmento social de idosos em nossa sociedade, não se trata de um processo de recuperação e resgate, uma vez que essa população não chegou a vivenciar melhores condições de existência. Trata-se de um processo evolutivo de construção dos direitos humanos a partir do acesso ao espaço público, fundamentado na consciência e na liberdade de pensamento conjugadas à ação. (MORETTI, 1998, p. 43, nosso grifo).

Em oposição à resposta 2 à pergunta $\mathrm{A}$ ("tá procupado com a velhice, hein???!!! kkkkkkkkkkk... se vc morrer novo, não vai passar por essa preocupação"), há uma verdade oculta que nos une a todos no combate à discriminação da pessoa idosa: nenhum de nós quer morrer jovem e todos queremos envelhecer dignamente. 


\title{
SEXUALITY AND AGEISM: an analysis of discourse on online discussion forum
}

\begin{abstract}
In this article we examine the discourses about sexuality and aging that emerge among users of an online discussion forum, a space where the lack of censorship allows them to reveal prejudices and to reinforce myths and stereotypes. For that purpose, eleven extracts (three questions and eight answers) from Yahoo-Respostas were collected in November 2007 from the usage of search words as "elder or aged or old + sex" and were confronted to other bibliographies. Despite the prevailing ageist discourse, of denial and exclusion, dissonant discourses begin to emerge, based on a new perspective, of affirmation and inclusion, arising from the contributions of Gerontology and Human Rights, which are not only areas of knowledge, but also ideologies in defense of diversity.

Keywords: Aging. Sex. Prejudice. Gerontology. Human Rights.
\end{abstract}

\section{REFERÊNCIAS}

ARAÚJO, Anna Cruz de. O Direito do Idoso na Ordem Internacional: uma contribuição ao ideário gerontológico, a partir dos Planos de Ação de Viena e Madri. 2005. 102 p. (Monografia de Conclusão de Curso) - Faculdade de Direito, Universidade da Amazônia, Ananindua, 2005.

BRASIL. Lei 10.741, de 1 de outubro de 2003. Dispõe sobre o Estatuto do Idoso e dá outras providências. Brasília, DF, 2003. Disponível em: <http://www.planalto.gov.br/ ccivil/LEIS/2003/L10.741.htm>. Acesso em: 13 nov. 2008

BRODGEN, Mike. Geronticide: killing the elderly. London: Jessica Kingsley, 2001.

CAMPOS, Ivelise. Ágoras Virtuais: espaços de discussão e debate na internet. In: Equipe de Psicólogos do Núcleo de Pesquisas em Psicologia e Informática. Psicologia e Informática: o ser humano diante das novas tecnologias. São Paulo: Oficina do Livro, 2004a. P. 143-146.

CAMPOS, Ivelise. Identidade Virtual: os nicknames e os personagens virtuais. In: Equipe de Psicólogos do Núcleo de Pesquisas em Psicologia e Informática. Psicologia e Informática: o ser humano diante das novas tecnologias. São Paulo: Oficina do Livro, 2004b. P. 117-126.

COCKERHAM, William. This Aging Society. 2nd ed. New Jersey: Prentice Hall, 1997. 
COSTA, Elisabeth Maria Sene. Gerontodrama: a velhice em cena: estudos clínicos e psicodramáticos sobre o envelhecimento e a terceira idade. São Paulo: Ágora, 1998.

FERRARI, Maria Auxiliadora. O Envelhecer no Brasil. O Mundo da Saúde, São Paulo, v. 23, n. 4, p. 197-203, jul./ago. 1999.

FERREIRA, Aurélio Buarque de Holanda. Novo Dicionário da Língua Portuguesa. 2. ed. rev. aum. Rio de Janeiro: Nova Fronteira, 2000.

FIORIN, Jose Luiz. Percurso Gerativo de Sentido. In: Elementos de Análise do Discurso. São Paulo: Contexto, 1990. P. 15-38.

FOUCAULT, Michel. A Ordem do Discurso. 3. ed. São Paulo: Loyola, 1996.

GUSMÃO, Neusa Maria. Infância e Velhice: desafios da multiculturalidade. In: GUSMÃO, Neusa (Org.). Infância e Velhice: pesquisa de idéias. Campinas: Alínea, 2003. P. 15-32.

IACUB, Ricardo. Erótica e velhice: perspectivas do Ocidente. São Paulo: Vetor, 2007.

LOPES, Ruth. Velhos "Indignos". Revista Kairós: Gerontologia, São Paulo, v. 1, n. 1, p. 69-77, 1998.

MELO, Cristina Teixeira Vieira de. A Análise do Discurso em Contraponto à Noção de Acessibilidade Ilimitada da Internet. In: MARCUSCHI, Luis Antônio; XAVIER, Antônio Carlos (Org.). Hipertexto e Gêneros Textuais. Rio de Janeiro: Lucerna, 2004.

MESSY, Jack. A Pessoa Idosa Não Existe: uma abordagem psicanalítica da velhice. São Paulo: Aleph, 1999.

MORETTI, Maria Ines P. Cidadania: a conquista de um espaço na sociedade para o envelhecimento. Revista Kairós: Gerontologia, São Paulo, v. 1, n. 1, p. 33-43, 1998.

ORLANDI, Eni. Tipologia de Discurso e Regras Conversacionais. In: A Linguagem e seu Funcionamento: as formas do discurso. 4. ed. Campinas: Pontes, 1996. P. 149-174.

PALMORE, Erdman. The Future of Ageism: issue brief. New York: International Longevity Center, 2004.

PEIXOTO, Clarice. Entre o Estigma e a Compaixão e os Termos Classificatórios: velho, velhote, idoso, terceira idade. In: LINS DE BARROS, Myriam (Org.). Velhice ou Terceira Idade? Estudos antropológicos sobre identidade, memória e política. Rio de Janeiro: FGV, 2007. P. 69-84.

WORLD ASSOCIATION FOR SEXUAL HEALTH. Declaração dos Direitos Sexuais. Mexico, DF, 1999. Disponível em: <http://www.worldsexology.org/about_sexualrights portuguese.asp $>$. Acesso em: 10 ago. 2007. 
YAHOO! RESPOSTAS. Idoso que Namora Menina Nova ta Procurando Sarna pra se Coçar? [S. 1.], 2007a. Disponível em: <http://br.answers.yahoo.com/question/index; ylt=AmiyAb1lCegocOzWT7x_Ep_x6gt.;_ylv=3?qid=20071120151954AAPyuNo $>$. Acesso em: 22 nov. 2007.

YAHOO! RESPOSTAS. Numa Sociedade Igualitária e Sexualmente Liberada, Quem Traça as Idosas? [S. 1.], 2007b. Disponível em: <http://br.answers.yahoo.com/question/ index?qid=20070524185804AAA1iYa $>$. Acesso em: 22 nov. 2007.

YAHOO! RESPOSTAS. Regras da Comunidade do Yahoo! Respostas. [S. 1.], c2008. Disponível em: $<\mathrm{http} / / /$ br.answers.yahoo.com/info/community_guidelines.php $>$. Acesso em: 05 dez. 2007.

YAHOO! RESPOSTAS. Será que Velho faz Sexo? Por ex: uma velha de 80 anos faria sexo? [S. 1.], 2006. Disponível em: <http://br.answers.yahoo.com/question/index?qid=20 061006125303AAVPykC>. Acesso em: 22 nov. 2007.

\section{Agradecimentos}

Uma versão preliminar deste trabalho foi originalmente apresentada ao Prof. Dr. José Guilherme Fernandes, a quem se agradece por comentários, sugestões e indicações de leitura.

Recebido em: 23-01-2008

$1^{a}$ revisão: 09-03-2008

Aceite final: 23-11-2008 